\title{
THE REGULATORY PROCESS
}

With Illustrations from Commercial Aviation 
THIS PAGE INTENTIONALLY LEFT BLANK 


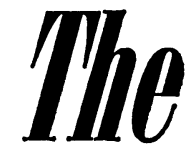

Regylatory

Process'

With Illustrations from

Commercial Aviation

By EMMETTE S. REDFORD

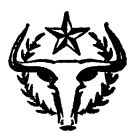

UNIVERSITY OF TEXAS PRESS

AUSTIN 
Standard Book Number 292-78413-9 Library of Congress Catalog Card No. 70-92158

Copyright @ 1969 by Emmette S. Redford All Rights Reserved 